\title{
Three dimensional ultrasound- its use in defining and prognosticating fibroid associated with pregnancy: one picture is worth more than a thousand words
}

\author{
Aarti Deenadayal Tolani ${ }^{1 *}$, Suhasini Donthi ${ }^{1}$, Kadambari $^{2}$, Mamata Deenadayal ${ }^{1}$
}

\begin{abstract}
${ }^{1}$ Department of Reproductive Medicine, ${ }^{2}$ Department of Obstetrics and Gynecology, Infertility Institute and Research Centre, Shenoy Hospitals, Hyderabad, Telangana, India
\end{abstract}

Received: 25 February 2018

Accepted: 28 March 2018

\section{*Correspondence: \\ Dr. Aarti Deenadayal Tolani, \\ E-mail: draarti@iirc.in}

Copyright: () the author(s), publisher and licensee Medip Academy. This is an open-access article distributed under the terms of the Creative Commons Attribution Non-Commercial License, which permits unrestricted non-commercial use, distribution, and reproduction in any medium, provided the original work is properly cited.

\begin{abstract}
Uterine fibroids are most frequent benign growths occur in female reproductive age with the frequency of $20-40 \%$. The fibroid incidence in pregnancy estimated to be 0.1 to $3.9 \%$. They affect the female fertility and embryo implantation rates after the assisted reproductive treatments. Although most of the uterine myomas are asymptomatic during pregnancy, seldom they lead to the various complications that harm the pregnancy. Henceforth it is advisable to diagnose the uterine myomas at early stages. Three-dimensional ultrasonography is excellent equipment producing high-resolution images in different panels. It is easily accessible, cost-effective and offers benefits for early diagnosis of uterine anomalies. In this case report, we emphasized on the early diagnosis of the uterine fibroid associated pregnancy that enabled the physician to manage the pregnancy without complications.
\end{abstract}

Keywords: Intramural fibroid, Gestational sac, Three-dimensional ultrasound, Trans vaginal

\section{INTRODUCTION}

Smooth muscle cells and fibrous connective tissue of the uterus turns in to firm compact tumors of different sizes and they are called as fibroids, uterine myomas, leiomyomas or fibromas.

The incidence of uterine fibroids is $20-40 \%$ in the reproductive age of the female. ${ }^{1}$ Fibroids associated pregnancies are considered to be high-risk pregnancies due to the increase incidences of spontaneous miscarriages, preterm labor, placenta abruption, malpresentation, labor dystocia, cesarean delivery, and postpartum hemorrhage.

The early diagnosis of location, size, and the number of fibroids in pregnant women is essential for the management and to avoid the aforementioned complications. Larger fibroids can be diagnosed during bimanual vaginal examination. X-ray, magnetic resonance imaging (MRI) and ultrasound are the different modalities used for the diagnosis of small fibroids. The drawbacks of X-ray and MRI include radiation hazards to the fetus and low accessibility and high cost respectively. Detection by ultrasound is non-invasive, simple, accessible and affordable comparatively.

In this case report, we present fibroid co-existing with pregnancy and its early detection by three-dimensional transvaginal ultrasonography.

\section{CASE REPORT}

A 33-year-old woman presented to Infertility Institute and Research Center, Hyderabad, India, with a positive pregnancy test. Initial baseline two dimensional (2D) 
trans-vaginal scan was performed which revealed an intrauterine gestational sac corresponding 7 weeks of gestation with an intramural fibroid (Figure-1).
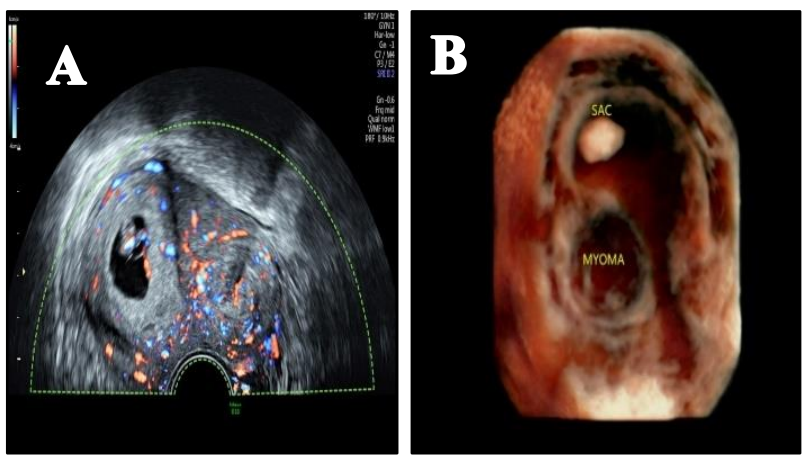

Figure 1: A) 2DTransvaginal Ultrasound with

Doppler of a single intrauterine pregnancy and its relationship to an intramural fibroid. B) 3D

Reconstruction of Figure-1 clearly outlining the relationship of the intra-uterine gestational sac with the uterine fibroid which is away from the junctional zone

A 3D Trans-vaginal ultrasound examination delineated the location of the gestational sac and the location of the fibroid and their relationship with each other. The 3D ultrasound also revealed the sac location in the fundal region and the intramural fibroid in the left lateral wall away from the junctional zone. This wonderful investigation helped us to give the patient a comprehensive picture regarding her pregnancy. The complications and risks associated with this condition were easily explained and understood by the patient and her husband with the help of the self-explanatory 3D ultrasound image. It was possible for us to share the scan picture with the patient's obstetrician to plan the further management of the fibroid complicating pregnancy clearly. Now she is 27 weeks pregnant with a healthy ongoing pregnancy. 3D is a wonderful tool for assessing, counseling and managing patients who require close monitoring. A $3 \mathrm{D}$ picture is worth more than a thousand words because a complex idea can be conveyed with just a single still image and that image of a subject conveys its meaning or essence more effectively than a description does.

\section{DISCUSSION}

The etiologies of uterine leiomyomas are unknown however the predisposing factors such as delayed childbearing, ethnicity, obesity, and genetics may contribute to the development of fibroids. ${ }^{2,3}$ Threedimensional ultrasound is an excellent, inexpensive and readily available diagnostic tool for the screening of the uterine leiomyomas. Among Trans abdominal (TAS) and Transvaginal (TVS), TVS is more sensitive and accurate particularly when the uterus is retroflexed and/or retroverted. Ultrasonography is completely operator dependent and hence it is crucial that the sonographer is well trained to diagnose the location and size of the fibroids. Fibroids that arise in the uterine wall can be intramural, submucosal and subserosal. Submucosal leiomyomas can be usually differentiated from the endometrium, however, differentiating them from polyps is difficult. In such cases hysterosonography is helpful in visualizing the endometrium clearly and differentiating submucosal leiomyomas from polyps. ${ }^{4}$ Most of the leiomyomas appear as well defined solid masses where the echogenicity is usually similar to the myometrium. But sometimes the echogenicity is hypoechoic or heterogeneous echogenic pattern or cystic changes may be seen. In such cases, color Doppler ultrasound typically shows circumferential vascularity. ${ }^{5}$

Approximately $10-30 \%$ of women with leiomyomas develop complications during pregnancy. Apart from the reasons like uterine distensibility and mechanical obstruction the precise mechanism by which the uterine leiomyomas induce obstetric complications is not completely understood. ${ }^{6}$ Studies reported that the spontaneous miscarriages are high in pregnant women with fibroids compared to the ones without fibroids. ${ }^{7}$ Although the size of the fibroid may not affect the pregnancy rate, the multiple numbers of fibroids may increase the miscarriages. ${ }^{7}$ As far as the location of the fibroid is concerned uterine corpus fibroid is riskier than the fibroids in the lower uterine segment or intramural or submucosal. ${ }^{8-11}$

The complications associated with fibroid present pregnancy include preterm labor, placental abruption, Placenta previa, fetal growth restriction, fetal malpresentation during delivery, postpartum hemorrhage and Retained placenta. Although the association between pregnancy and fibroid is not extremely rare, the complications are frequent and have to be detected at early stages to avoid maternal and fetal morbidity. Threedimensional ultrasound is a useful tool for the diagnosis, measurement and vascularity index assessment of the leiomyomas.

\section{Funding: No funding sources Conflict of interest: None declared Ethical approval: Not required}

\section{REFERENCES}

1. Vitale SG, Tropea A, Rossetti D, Carnelli M, Cianci A. Management of uterine leiomyomas in pregnancy: review of literature. Updates Surg. 2013; 65:179-82.

2. Flake GP, Andersen J, Dixon D. Etiology and pathogenesis of uterine leiomyomas: a review. Environ Health Perspect. 2003;111:1037-54.

3. Vollenhoven BJ, Lawrence AS, Healy DL. Uterine fibroids: a clinical review. Br J Obstet Gynaecol. 1990; 97:285-98.

4. Cicinelli E, Romano F, Anastasio PS, Blasi N, Parisi C, Galantino P. Transabdominal sonohysterography, transvaginal sonography, and hysteroscopy in the 
evaluation of submucous myomas. Obstet Gynecol. 1995;85:42-7.

5. Fleischer AC. Color Doppler sonography of uterine disorders. Ultrasound Q. 2003;19:179-89.

6. Rice JP, Kay HH, Mahony BS. The clinical significance of uterine leiomyomas in pregnancy. Am J Obstet Gynecol. 1989;160:1212-6.

7. Benson CB, Chow JS, Chang-Lee W, Hill JA 3rd, Doubilet PM. Outcome of pregnancies in women with uterine leiomyomas identified by sonography in the first trimester. J Clin Ultrasound. 2001 Jun; 29:261-4.

8. Klatsky PC, Tran ND, Caughey AB, Fujimoto VY. Fibroids and reproductive outcomes: a systematic literature review from conception to delivery. Am J Obstet Gynecol. 2008;198:357-66.

9. Casini ML, Rossi F, Agostini R, Unfer V. Effects of the position of fibroids on fertility. Gynecol Endocrinol. 2006;22:106-9.
10. Goldenberg M, Sivan E, Sharabi Z, Bider D, Rabinovici J, Seidman DS. Outcome of hysteroscopic resection of submucous myomas for infertility. Fertil Steril. 1995;64:714-6.

11. Bernard G, Darai E, Poncelet C, Benifla JL, Madelenat P. Fertility after hysteroscopic myomectomy: effect of intramural myomas associated. Eur J Obstet Gynecol Reprod Biol. 2000;88:85-90.

Cite this article as: Tolani AD, Donthi $S$,

Kadambari, Deenadayal M. Three dimensional ultrasound- its use in defining and prognosticating fibroid associated with pregnancy: one picture is worth more than a thousand words. Int J Reprod Contracept Obstet Gynecol 2018;7:2046-8. 